\title{
Acne scars in 18-year-old male adolescents: a population-based study of prevalence and associated factors*
}

\author{
Fernanda Tcatch Lauermann ${ }^{1}$ \\ Rodrigo Pereira Duquia ${ }^{3}$ \\ Juliano de Avelar Breunig ${ }^{5}$
}

\author{
Hiram Larangeira de Almeida Jr. ${ }^{2}$ \\ Paulo Ricardo Martins de Souza ${ }^{4}$
}

\begin{abstract}
BACKGROUND: Acne vulgaris is a pilosebaceous follicle disorder affecting over $85 \%$ of adolescents to some degree. It frequently causes psychological distress that may persist into adulthood due to scarring. Little information about post-acne scarring epidemiology is available.

Oвјестіvеs: To describe prevalence, distribution patterns and associated factors of acne scarring in young males, drawing on a representative population sample from a southern Brazilian city.

Methods: A cross-sectional study was undertaken during presentation for military service, which is compulsory for all 18-year-old males. A questionnaire was applied, covering topics like diet, smoking habits, ethnicity, family structure, socio-economic level, as well as specific questions about active acne and resulting scars. Dermatologists conducted the clinical examination.

RESULTS: A total of 2,201 male adolescents were interviewed and examined. The overall prevalence of acne scarring was $22 \%$. The malar region was the most frequently involved, present in $80 \%$ of affected individuals, followed by the frontal region $(31.5 \%)$, back $(17 \%)$, anterior chest $(8.2 \%)$ and mentonian region $(6.4 \%)$. Correlation between the intensity of clinical acne and the presence of scars was found, but no association was observed with educational level, smoking, ethnicity, obesity or socio-economic status.

Conclusions: There is a high prevalence of acne scars among this population. This is the first study to ascertain a correlation between acne scarring and factors such as socio-economic status and educational level. The direct relation between acne severity and scarring indicates that prompt and effective treatment is the best way to reduce scarring.
\end{abstract}

Keywords: Acne vulgaris; Cicatrix; Epidemiology

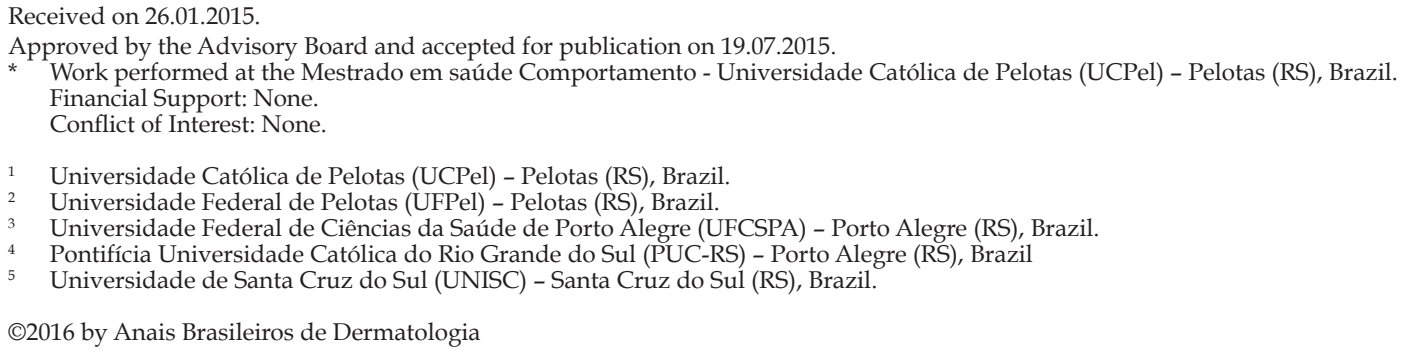




\section{INTRODUCTION}

Acne vulgaris is a pilosebaceous follicle disorder affecting over $85 \%$ of adolescents to some degree. ${ }^{1-3} \mathrm{Mul}-$ tiple factors are involved in the pathogenesis of acne, but the key points are: follicular hyperkeratinization, increased sebum production, Propionibacterium acnes colonization and inflammatory response. ${ }^{4}$ Further, the condition surfaces during a period of life typified by self-image concerns, and can thus be emotionally devastating. In the vast majority of cases, spontaneous resolution occurs, though up to $14 \%$ of individuals remain with signs of the disease through adulthood. ${ }^{5-7}$ This contradicts the common misconception that acne is a self-limited condition restricted to adolescence, and such instances have spawned the current concept of acne as a chronic disease. ${ }^{8-10}$

When acne resolves, the psychological distress nonetheless persists due to scarring that - rather than improving over time - often worsens as the natural aging process unfolds. ${ }^{11}$ The psychological impact of acne and its scars is well-documented, while the emotional imbalance it causes is comparable to that of systemic diseases such as diabetes, asthma, arthritis and epilepsy. ${ }^{12}$ Even the risk of suicide has been found to increase in individuals suffering from acne. ${ }^{12,13}$

Little information about post-acne scarring is available. Layton et al. have demonstrated a correlation between scarring and disease severity, as well as delayed initial treatment. ${ }^{14}$ Both mild superficial lesions and severe nodular acne can cause scarring. ${ }^{14}$

Well-delineated studies on acne scarring are scarce. ${ }^{15}$ Our study seeks to describe the characteristics and distribution patterns of acne scarring in young males, drawing on a representative population sample from the city of Pelotas.

\section{METHODS}

This cross-sectional study was undertaken during presentation for military service in Pelotas, which is compulsory for all males when they turn 18 . Trained interviewers applied a questionnaire covering topics like diet, smoking habits, ethnicity, family structure, socio-economic level, as well as specific questions about active acne and resulting scars. Skin examinations were conducted by a group of four dermatologists, all with over 4 years of training. Agreement among these professionals had kappa values $>0.80$.

The face was divided into five regions (frontoparietal, right and left malar, nasal and mentonian) and the chest into two regions (anterior and posterior). Adolescents with at least one non-inflammatory or inflammatory acne lesion were considered clinical cases of acne, while the presence of acne scars was classified as none, $<5$ lesions and $\geq 5$ lesions. Scar types were not assessed. Exclusion criteria included cognition defi- ciency and current treatment for acne.

Data were entered twice using Epi-Info version 6.04 (Centers for Disease Control and Prevention, Atlanta, GA, USA), with an automatic check for consistency and amplitude. Thereafter, data were transferred to STATA Version 9.0 (StataCorp LP, College Station, TX, USA), on which all calculations were run.

The study protocol was approved by the Ethics Committee of the Santa Casa Hospital of Pelotas, and adhered to the guidelines of the Declaration of Helsinki. Written detailed consent was duly obtained from each participant before enrollment in the study.

\section{RESULTS}

A total of 2,201 male adolescents were enrolled in our study. The overall acne prevalence was $89.4 \%$ and scarring - concurrently with clinical acne or not was present in $22 \%$ (483) of participants. Among those presenting with scars, the malar region was the most frequently affected: $81.8 \%$ had scars on the right malar (37.7\% with under 5 scars $/ 44.1 \%$ with 5 or more), while $80.5 \%$ had scars on the left malar (36.6\% / 43.9\%). The frontoparietal region exhibited scars in 31.5\% $(15.3 \% / 16.2 \%)$, followed by the mentonian area with $6.4 \%(3.1 \% / 3.3 \%)$. Nasal scarring occurred in only five participants (1\%). Figure 1 demonstrates scarring distribution on the face. Scars on the anterior chest were present in $8.2 \%(1.2 \% / 7 \%)$, and scarring on the back affected $17 \%$ (1\%/16\%).

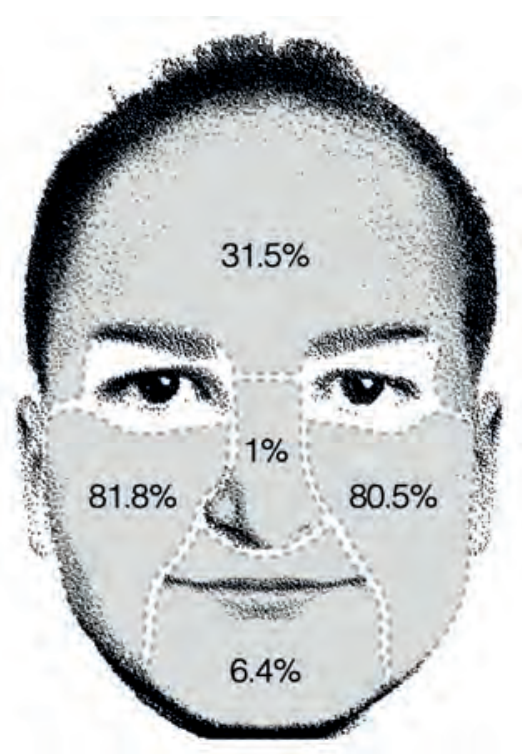

FIGURE 1: Frequency of acne scarring according to facial region 
The chi-square test for linear tendency was performed to analyze the association between intensity of active acne and the presence of scars, yielding significant results. Among participants with under 5 inflammatory lesions, $21.6 \%$ had scars; of those with 6 to 10 inflammatory lesions, $23 \%$ had scars; while $55.4 \%$ of individuals with 11 or more active acne lesions, presented with scars $(p<0.000)($ Table 1$)$.

Family income, educational level, smoking, ethnicity and body mass index were not found to be statistically correlated to acne scarring in this sample (Table 1).

TABLE 1: Results showing association only with the number of active acne lesions

\begin{tabular}{lcc} 
Variables & Acne Scar & P value \\
\hline Socio-economic level (\&) & Yes (\%) & \\
A & & $\mathrm{P}=0.9$ * \\
B & 21.97 & \\
C & 21.86 & \\
D and E & 22.05 & \\
Smoking & 21.89 & \\
Yes & & \\
No & 22.94 & $\mathrm{P}=0.6^{*}$ \\
Educational level & 22.17 & \\
Up to 8 years & & \\
9 years or more & 21.62 & $\mathrm{P}=0.7$ * \\
Ethnicity & 22.39 & \\
White & & \\
Non-white & 22.60 & $\mathrm{P}=0.3$ * \\
Body mass index & 20.52 & \\
1st Tertile & & \\
2nd Tertile & 21.83 & $\mathrm{P}=0.5^{*}$ \\
3rd Tertile & 23.36 & \\
Number of inflammatory lesions & \\
$<$ 5 & 21.60 & $\mathrm{P}<0.0001 \#$ \\
6 to 10 & 23.0 & \\
$>$ 10 & 55.40 &
\end{tabular}

\footnotetext{
* Fisher's exact test

\# Socio-economic levels were assessed using the test for linear tendency and the Classification of the Brazilian Association of Research Companies, taking into account income, properties and educational level; $\mathrm{A}$ is the highest.
}

\section{DISCUSSION}

Overall prevalence and factors associated with acne scarring have yet to be entirely clarified. In a study comprising 3,305 French women aged 25-40 years, $49 \%$ of participants declared they had acne sequelae in a self-applied questionnaire. ${ }^{9}$ Another self-reported survey conducted among adolescents in Hong Kong found a scar prevalence of $52.6 \%{ }^{16}$

In a study where 749 subjects aged over 25 were examined by dermatologists, Goulden et al. ${ }^{6}$ recorded a scar prevalence of $11 \%$ in males and $14 \%$ in females. An Australian survey that included 266 school students aged $16-18$ indicated a prevalence of $26.1 \%$, similar to ours. ${ }^{17}$ Both studies relied on clinical examination by dermatologists, but unlike our research, the Australian authors evaluated only the facial and neck area ${ }^{6,17}$ In a study conducted by Layton et al., out of 185 patients with acne attending the dermatology department, 95\% exhibited acne scarring to some degree. ${ }^{14}$ The age range was not declared. ${ }^{14}$

Comparison with post-acne scars studies is difficult due to the wide range of methods, population age, and case definition. ${ }^{15,18}$ Distinct authors have classified or merely described acne scars in an incomplete and non-standardized manner. The most widespread classification used among dermatologists was created by Jacob in 2001, comprising the terms ice-picks, rolling, and boxcar. ${ }^{16} \mathrm{~A}$ recent publication evaluated concurrency within a group of dermatologists as they classified acne scars using images in an electronic questionnaire. ${ }^{12}$ The result showed that, even among experts, no general consensus exists on adequate classification of lesions. ${ }^{19}$

Factors such as socio-economic status, educational level, smoking and obesity were investigated with respect to acne scarring. No association was found, which may be due to the homogeneity of the population that made up the sample (all individuals were males of the same age). These factors may prove important in non-homogeneous, population-based studies.

Why patients develop acne scarring remains controversial. While examining biopsies from acne lesions on the backs of patients (exhibiting scarring or not), Holland et al. found an enhanced - but effective - unspecific, inflammatory infiltrate in the pilosebaceous follicles of patients without scarring. However, those with scarring presented with a specific, prolonged immune response. ${ }^{20}$ Our study demonstrated an association between the number of inflammatory lesions and the presence of scars. Significant involvement of active lesions in the malar and frontal region, as well as on the back, had already been reported. ${ }^{21}$

Direct links between acne severity and scarring encourage a prompt and aggressive approach to clinical acne, representing perhaps the most effective way 
of preventing scarring.

The observation that populations with non-westernized dietary habits did not exhibit acne has led to several studies exploring this possible correlation. ${ }^{22-24}$ The most consistent evidence indicates that milk-derived products and diets with high glycemic levels are comedogenic. ${ }^{25-27}$ The physiopathology implies stimulation of sebaceous secretion and follicular hyper- keratinization, due to an elevation in androgenic hormones, in turn caused by high Insulin-like Growth Factor-1 (IGF-1) plasma levels. ${ }^{28}$ Nevertheless, a clear correlation between acne and obesity has never been confirmed, which demonstrates that the issue is not how much we eat, but what we eat". ${ }^{29}$ Accordingly, no association between obesity and acne scarring was found in our study.
Treatment for acne scarring can be frustrating and fruitless. Our data support the need for precocious treatment of severe acne, before the onset of scarring. ${ }^{0,31}$

\section{CONCLUSIONS}

The male population studied exhibited a high prevalence of acne scars. This study investigated the links between acne scarring and factors such as socio-economic status, educational level and body mass index, which were not associated with the outcome. The direct association between severity of inflammatory acne lesions and scarring indicates that prompt and effective treatment is the best way to reduce scarring.] 


\section{REFERENCES}

1. Yahya $\mathrm{H}$. Acne vulgaris in nigerian adolescents--prevalence, severity, beliefs, perceptions, and practices. Int J Dermatol. 2009;48:498-505.

2. Ghodsi SZ, Orawa H, Zouboulis CC. Prevalence, severity, and severity risk factors of acne in high school pupils: A community-based study. J Invest Dermatol. 2009;129:2136-41.

3. Isaacsson VC, Almeida HL Jr, Duquia RP, Breunig Jde A, Souza PR. Dissatisfaction and acne vulgaris in male adolescents and associated factors. An Bras Dermatol. 2014;89:576-9.

4. Gollnick H, Cunliffe W, Berson D, Dreno B, Finlay A, Leyden JJ, et al. Management of acne: A report from a global alliance to improve outcomes in acne. J Am Acad Dermatol. 2003;49:S1-37.

5. Collier CN, Harper JC, Cafardi JA, Cantrell WC, Wang W, Foster KW, et al. The prevalence of acne in adults 20 years and older. J Am Acad Dermatol. 2008;58:56-9.

6. Goulden V, Stables Gl, Cunliffe WJ. Prevalence of facial acne in adults. J Am Acad Dermatol. 1999;41:577-80.

7. Capitanio B, Sinagra JL, Bordignon V, Cordiali Fei P, Picardo M, Zouboulis CC. Underestimated clinical features of postadolescent acne. J Am Acad Dermatol. 2010;63:782-8.

8. Poli F., Pernet, A.M., Verschoore, M. Epidemiological study on adult acne. J Am Acad Dermatol. 2007;56:AB13

9. Poli F, Dreno B, Verschoore M. An epidemiological study of acne in female adults: Results of a survey conducted in France. J Eur Acad Dermatol Venereol. 2001;15:541-5

10. Thiboutot D, Gollnick H, Bettoli V, Dréno B, Kang S, Leyden JJ, et al. New insights into the management of acne: An update from the global alliance to improve outcomes in acne group. J Am Acad Dermatol. 2009;60:S1-50.

11. O'Daniel TG. Multimodal management of atrophic acne scarring in the aging face. Aesthetic Plast Surg. 2011;35:1143-50.

12. Mallon E, Newton JN, Klassen A, Stewart-Brown SL, Ryan TJ, Finlay AY. The quality of life in acne: A comparison with general medical conditions using generic questionnaires. Br J Dermatol. 1999;140:672-6.

13. Halvorsen JA, Stern RS, Dalgard F, Thoresen M, Bjertness E, Lien L.. Suicidal ideation, mental health problems, and social impairment are increased in adolescents with acne: A population-based study. J Invest Dermatol. 2011;131:363-70.

14. Layton AM, Henderson CA, Cunliffe WJ. A clinical evaluation of acne scarring and its incidence. Clin Exp Dermatol. 1994 Jul;19(4):303-8.

15. Kadunc BV, Trindade de Almeida AR. Surgical treatment of facial acne scars based on morphologic classification: A Brazilian experience. Dermatol Surg. 2003;29(:1200-9.

16. Yeung CK, Teo LH, Xiang LH, Chan HH. A community-based epidemiological study of acne vulgaris in hong kong adolescents. Acta Derm Venereol. 2002;82:104-7.

17. Kilkenny M, Merlin K, Plunkett A, Marks R. The prevalence of common skin conditions in australian school students: 3 . Acne vulgaris. $\mathrm{Br} \mathrm{J}$ Dermatol. 1998;139:840-5.

18. Jacob Cl, Dover JS, Kaminer MS. Acne scarring: A classification system and review of treatment options. J Am Acad Dermatol. 2001;45:109-17.

19. Finlay AY, Torres V, Kang S, Bettoli V, Dreno B, Goh CL, et al. Classification of acne scars is difficult even for acne experts. J Eur Acad Dermatol Venereol. 2013;27:391-3.

20. Holland DB, Jeremy AH, Roberts SG, Seukeran DC, Layton AM, Cunliffe WJ. Inflammation in acne scarring: A comparison of the responses in lesions from patients prone and not prone to scar. Br J Dermatol. 2004;150:72-81.

21. Duquia RP, de Almeida HL Jr, Breunig JA, Souzat PR, Göellner CD. Most common patterns of acne in male adolescents: A population-based study. Int J Dermatol. 2013:52:550-3.

22. Cordain L, Lindeberg S, Hurtado M, Hill K, Eaton SB, Brand-Miller J. Acne vulgaris: A disease of western civilization. Arch Dermatol. 2002;138:1584-90.

23. Schaefer 0. When the eskimo comes to town. Nutr Today. 1971;6:8-16.

24. Verhagen AR, Koten JW, Chaddah VK, Patel RI. Skin diseases in kenya: A clinical and histopathological study of 3,168 patients. Arch Dermatol. 1968;98:577-86.
25. Reynolds RC, Lee S, Choi JY, Atkinson FS, Stockmann KS, Petocz P, et al. Effect of the glycemic index of carbohydrates on acne vulgaris. Nutrients. 2010;2:1060-72.

26. Berra B, Rizzo AM. Glycemic index, glycemic load: New evidence for a link with acne. J Am Coll Nutr. 2009;28:450S-454S.

27. Adebamowo CA, Spiegelman D, Danby FW, Frazier AL, Willett WC, Holmes MD. High school dietary dairy intake and teenage acne. J Am Acad Dermatol. 2005;52:207-14

28. Cordain L. Implications for the role of diet in acne. Semin Cutan Med Surg 2005;24:84-91.

29. Costa A, Lage D, Moisés TA. Acne and diet: Truth or myth? An Bras Dermatol 2010;85:346-53.

30. Goodman GJ. Postacne scarring: A review of its pathophysiology and treatment Dermatol Surg. 2000;26:857-71.

31. Layton AM. Optimal management of acne to prevent scarring and psychological sequelae. Am J Clin Dermatol. 2001;2:135-41.
MAILING ADDRESS:
Hiram Larangeira de Almeida Jr
Rua Gonçalves Chaves, 373 - Centro
96015-560 - Pelotas - RS
Brazil
E-mail: hiramalmeidajr@hotmail.com

How to cite this article: Lauermann FT, Almeida Jr HL, Duquia RP, Martins de Souza PR, Breunig JA. Acne scars in 18-year-old male adolescents: a population-based study of prevalence and associated factors. An Bras Dermatol. 2016;91(2):291-5. 